\title{
POLITICAL DECLARATION AND PLAN OF ACTION ON INTERNATIONAL COOPERATION TOWARDS AN INTEGRATED AND BALANCED STRATEGY TO COUNTER THE WORLD DRUG PROBLEM
}

High-level segment 

POLITICAL DECLARATION AND PLAN OF ACTION

ON INTERNATIONAL COOPERATION TOWARDS

AN INTEGRATED AND BALANCED STRATEGY

TO COUNTER THE WORLD DRUG PROBLEM

\section{High-level segment Commission on Narcotic Drugs}

\section{Vienna, 11-12 March 2009}

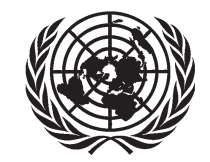

UNITED NATIONS

New York, 2009 
This publication has been made possible thanks to a contribution by the European Union. 


\section{Foreword}

At the high-level segment of the fifty-second session of the Commission on Narcotic Drugs, held on 11 and 12 March 2009, Heads of State, ministers and government representatives from 132 States gathered to evaluate progress made since 1998 towards meeting the goals and targets established at the twentieth special session of the General Assembly, devoted to countering the world drug problem together; to identify future priorities and areas requiring further action and goals and targets to be established for drug control beyond 2009; and to adopt a political declaration and other measures to enhance international cooperation.

Member States adopted the Political Declaration and Plan of Action on International Cooperation towards an Integrated and Balanced Strategy to Counter the World Drug Problem, which is contained in the present publication.

The adoption of the Political Declaration and Plan of Action some 10 years after the twentieth special session of the General Assembly of 1998 has given fresh impetus to international drug control. It is now incumbent on Member States to follow up and implement those international commitments in order to enhance progress and thus address the challenges posed by the world drug problem effectively in the coming years. 


\section{Contents}

Foreword iii

Statement by the United Nations Under-Secretary-General and Executive Director of the United Nations Office on Drugs and Crime, Mr. Antonio Maria Costa, to the Opening of the high-level segment of the Commission on Narcotic Drugs at its fifty-second session

Political Declaration and Plan of Action on International Cooperation towards an Integrated and Balanced Strategy to Counter the World Drug Problem 7

$\begin{array}{ll}\text { Political Declaration } & 7\end{array}$

$\begin{array}{ll}\text { Plan of Action } & 17\end{array}$

$\begin{array}{lll}\text { Part I. Demand reduction and related measures } & 17\end{array}$

A. Reducing drug abuse and dependence through a comprehensive approach $\quad 17$

$\begin{array}{ll}\text { Part II. Supply reduction and related measures } & 27\end{array}$

B. Reducing the illicit supply of drugs $\quad 27$

C. Control of precursors and of amphetamine-type stimulants 34

D. International cooperation on eradicating the illicit cultivation of crops used for the production of narcotic drugs and psychotropic substances and on alternative development

Part III. Countering money-laundering and promoting judicial cooperation to enhance international cooperation

E. Countering money-laundering $\quad 49$

F. Judicial cooperation $\quad 52$ 



\section{Statement by the United Nations Under-Secretary-General and Executive Director of the United Nations Office on Drugs and Crime, Mr. Antonio Maria Costa, to the Opening of the high-level segment of the Commission on Narcotic Drugs at its fifty-second session}

This Session of the Commission on Narcotic Drugs coincides with the centenary of the Shanghai International Opium Commission (1909). It is also the opportunity to review progress made since the Special Session of the United Nations General Assembly (UNGASS in 1998) on drugs.

The question in everybody's mind is simple: have these multiple efforts reduced the world drug problem? Up front, let me report what the statistics say: if we look at the physical dimensions of the problem (tons of production and numbers of addicts), we can state that humanity has made measurable progress. If we look however at the bigger picture, namely at the impact of drugs on security and development, the assessment is more complex - and not benign. Let me explain how I see the situation and what can be done.

\section{Measurably lower drug supply}

Look first at supply. More than 40,000 tons of opium were produced a century ago. They are now down by three quarters, to 10,000 tons concentrated in Southern Afghanistan. Coca cultivation in the Andes is down by almost a fifth since 10 years ago (1999). In both regions illicit crops take place in areas infested by armed groups who protect, even promote the drug trade.

Above all, in the past 10 years, we have learned what has to be done to curtail drug cultivation: (a) re-establish government control over the territory, so as to bring security; and $(b)$ promote development, so as to eradicate poverty and not only drugs. The steep drop in opium cultivation in the Golden Triangle over the past decade (from 190 to 30,000 ha) was indeed based on two pillars: growth and stability.

Yet, containing a problem is not the same thing as solving it. Every year world markets are still supplied with about 1,000 tons of heroin (equivalent), another 1,000 tons of cocaine and untold volumes of marijuana, cannabis resin and synthetic drugs. So there is still much more to be done. 


\section{Reducing demand from a health perspective}

What about demand for drugs? Our statistics are as robust as they could possibly be, and I challenge our critics to provide better ones. They confirm that worldwide addiction to illicit drugs has stabilized since a few years. It is falling for some types of drugs, and/ or in some parts of the world, but rising in others. International controls have limited the number of people who take illicit drugs to a small fraction of the world's adult population, much smaller than the number of people who use, and are killed by, other addictive substances like tobacco and alcohol. The roaring drug markets recorded at the beginning, as well as at the end of the 20th century have been tamed, but are certainly not bankrupt.

UNGASS must have played a role in this. Most importantly, UNGASS has increased awareness that drug dependence is an illness. The United Nations Office on Drugs and Crime (UNODC) works with governments to place health at the centre of drug control, so as to put addicts in the hands of doctors rather than policemen.

In the period ahead, a greater commitment is needed for prevention, treatment, and harm reduction - in an integrated, rather than mutually exclusive way. For this, UNODC has teamed up with the World Health Organization (WHO) to scale-up programmes around the world, and with UNAIDS to reduce the risk of HIV.

\section{A disturbing consequence of drug control}

The UNGASS experience taught us that the drug problem has to be tackled at both ends: (a) more development assistance to reduce supply, and (b) more attention on health to lower demand. Further progress in these two areas would affect the intermediate stage: $(c)$ it would curtail the drug trade. Let's face it. While the drug regime has kept under control the otherwise enormous health threat posed by drugs, it has also had a dramatic unintended consequence: a criminal market of macroeconomic size. According to our estimates, the illicit global drug trade is valued at over US $\$ 300$ billon a year. If it were a country, its gross national product (GNP) would be listed as 21 st in the world-right after Sweden.

The drug economy is more than just mafia cartels buying estates, businesses and aircrafts. They also buy officials, elections and parties. In a word, they buy power. Here is where the drug industry threatens security and development, in countries already stricken by poverty, unemployment and the HIV pandemic. This happens both where illicit crops are grown (in West Asia and the Andes), and where they are trafficked through (West Africa, Central America, the Caribbean and South-East Europe).

\section{What to do? Avoid extreme positions}

The crime crisis generates emotional responses. On one extreme, and perhaps out of frustration, ordinary people call for retribution-an eye for an eye, they say. This 
misunderstands the nature of addiction, abdicates the state's duty to protect its citizens, and violates human rights. Although drugs and crime kill, governments should not kill because of them.

On the other extreme, a vocal pro-drug lobby argues that the damage done by drug control is greater than the harm caused by drugs. Legalize drugs, they say, to eliminate crime-namely, toss the proverbial baby out with the bath water!

I suggest an approach that is not ideological, or emotional. Drugs are not harmful because they are controlled - they are controlled because they are harmful. The fact that certain unlawful transactions are hard to control doesn't mean that they should be made legal. Should humanity accept paedophilia, human trafficking, or arms smuggling out of a naïve sense of market inevitability or intractability? Lifting the controls on drugs would reveal a state's impotence to fight organized crime or protect the health of its citizens.

It is incumbent on governments to achieve both objectives: to protect a public good (health), and contain one of the world's foremost public bads (crime). It is rewarding to know that no country in this Commission disagrees with this view. Recent referenda in Europe are another bellwether, with the majority of public opinion stating loud and clear that: a policy change is needed against crime, not in favour of drugs.

We should invest in the solid middle ground between: $(a)$ criminalization of drug users and $(b)$ legalization of its use, by framing our collective efforts against drugs less like a war, and more like an effort to cure a social disease. By way of metaphor, let us say that the world is afflicted with drug addiction (the disease), and the drug control system (the cure) has had a dramatic side effect (a huge criminal market). The blueprint I propose is detailed in our recent paper: Organized Crime and its Threat to Security. Here, I will only sketch the arguments.

\section{Integrated, instead of disjointed, actions}

First prong: measures to control drugs must be conceived as part of an integrated strategy. At present, drug control is a patchwork, with disjointed actions that address only some aspects of supply (eradicating crops, rather than poverty); displace the drug trade problem (from one country, or substance to another); or use a hammer instead of a chisel (criminalizing demand, rather than treating it).

This compartmentalization doesn't work. Drug markets (and their mafias) are integrated in their logistics, financing, marketing and bribery power. They do not stop at borders. Governments need to do the same. UNODC has been pro-active in this respect. We have brokered the Paris Pact as well as regional intelligence centres in Central Asia (CARICC) and the Gulf (GCCI) to stem the flow of Afghan heroin. We are promoting similar regional cooperation in the Balkans, West Africa, the Caribbean and Central America. Why not do the same in the Andean region and in South-East Asia? 
Legal instruments to make these multi-tier arrangements work already exist. The United Nations Convention against organized crime, and especially its Protocol on Firearms, provides the platform for joint, rapid-impact action. Yet, this Protocol is not being implemented: look at the situation in Central America, where the flows of drugs to the North and of guns to the South undermine the security of nations. I urge all countriesespecially the arms producers - to ratify and implement the Firearms Protocol.

\section{Community resistance}

Now, the second prong. Drugs infect societies through open wounds. Similarly, crime cartels rule out-of-control regions (where there is supply), vulnerable areas (along trade routes), and derelict ghettos (where there is demand). Violence, instability, even terrorism are their direct cause, and consequence. Yet, like addiction, crime can be prevented and cured. The challenge is to reintegrate marginalized segments of society and draw them into, rather than push them out, of the law.

Socio-economic measures, in addition to law enforcement, have proven effective at the beginning of the drug cycle (with development assistance offered to farmers) as well as at the end of the cycle (with health measures offered to addicts). Urban populations, caught in the midst of drug wars deserve the same help.

Indeed, the largest share of the world's drug trade and abuse can be traced to a few blocks, in a few neighbourhoods of a few big cities. The key to regaining control of these areas is for law enforcement, combined with social reintegration, to create viable alternatives for young people who are lost to addiction, or who have become urban child soldiers of crime syndicates. In a rapidly urbanizing world, drug control will be won, or lost, in the cities.

\section{Use existing legal instruments}

The drug trade not only infects people: it also corrupts governments, together with business and finance. Nations need to improve governance so as to bolster resistance to drug cartels armed with war-chests worth billions of dollars. This leads me to the third prong: strengthening resistance mechanisms among nations by using existing instruments: the United Nations Conventions against crime and corruption.

These instruments were designed to deal with the world mafias that traffic drugs, arms, and people. Yet, many governments are not taking them seriously. While ghettos burn, West Africa is under attack, drug cartels threaten Central America, and drug money penetrates bankrupt financial institutions, there are large gaps in the implementation of the Palermo and the Merida Conventions. Their rules of engagement are not yet agreed upon, years after their entry into force. As a result, a number of countries now face a crime situation largely caused by their own choice. This is bad enough. Worse is the fact that, quite often, vulnerable neighbours pay an even greater price. 


\section{Beyond containment}

Ladies and gentlemen, the nations gathered in this historic session of the Commission on Narcotic Drugs (CND) unanimously support the United Nations treaties against drugs. The Political Declaration confirms this. Yet the drug conventions are under attack due to the emergence of drug cartels powerful enough to affect politics and businessand to cause a panic reaction in public opinion. The cartels undermine security and development, causing some people to make a dangerous wager in favour of legalization. This malaise is not the fault of the founding fathers of drug control. It is an inescapable result of inadequate implementation of existing crime control agreements, and the unwillingness to examine stronger measures against money-laundering and cyber-crime. History will judge us severely unless we protect more effectively health, security and development. 



\section{Political Declaration and Plan of Action on International Cooperation towards an Integrated and Balanced Strategy to Counter the World Drug Problem}

\section{Political Declaration}

One decade after the commitments made at the twentieth special session of the General Assembly ${ }^{1}$ to address the world drug problem, ${ }^{2}$ notwithstanding the everincreasing efforts and progress made by States, relevant international organizations and civil society, the drug problem continues to pose a serious threat to the health, safety and well-being of all humanity, in particular youth, our most precious asset. Furthermore, the world drug problem undermines sustainable development, political stability and democratic institutions, including efforts to eradicate poverty, and threatens national security and the rule of law. Drug trafficking and abuse pose a major threat to the health, dignity and hopes of millions of people and their families and lead to the loss of human lives. We are determined to tackle the world drug problem and to actively promote a society free of drug abuse in order to ensure that all people can live in health, dignity and peace, with security and prosperity; therefore:

\section{We, the States Members of the United Nations,}

Gravely concerned about the growing threat posed by the world drug problem, having assembled, in a spirit of trust and cooperation, at the high-level segment of the fifty-second session of the Commission on Narcotic Drugs to decide on future priorities and urgent action to counter the world drug problem beyond 2009, and mindful of the important lessons learned from the implementation of the Political Declaration, action plans and guidelines adopted by the General Assembly at its twentieth special session with the aim of achieving measurable results,

Fully aware that the world drug problem remains a common and shared responsibility that requires effective and increased international cooperation and demands an integrated, multidisciplinary, mutually reinforcing and balanced approach to supply and demand reduction strategies,

\footnotetext{
${ }^{1}$ See General Assembly resolutions S-20/2, S-20/3 and S-20/4 A to E.

${ }^{2}$ The illicit cultivation, production, manufacture, sale, demand, trafficking and distribution of narcotic drugs and psychotropic substances, including amphetamine-type stimulants, the diversion of precursors and related criminal activities.
} 
1. Reaffirm our unwavering commitment to ensure that all aspects of demand reduction, supply reduction and international cooperation are addressed in full conformity with the purposes and the principles of the Charter of the United Nations, international law and the Universal Declaration of Human Rights ${ }^{3}$ and, in particular, with full respect for the sovereignty and territorial integrity of States, the principle of non-intervention in the internal affairs of States, all human rights, fundamental freedoms, the inherent dignity of all individuals and the principles of equal rights and mutual respect among States;

2. Reaffirm also that the ultimate goal of both demand and supply reduction strategies and sustainable development strategies is to minimize and eventually eliminate the availability and use of illicit drugs and psychotropic substances in order to ensure the health and welfare of humankind and encourage the exchange of best practices in demand and supply reduction, and emphasize that each strategy is ineffective in the absence of the other;

3. Assert that the world drug problem is most effectively addressed in a multilateral setting and that the three international drug control conventions ${ }^{4}$ and other relevant international instruments remain the cornerstone of the international drug control system, and urge all Member States that have not yet done so to consider taking measures to ratify or accede to those instruments;

4. Support the traditional and established supplier countries in maintaining a balance between the licit supply of and demand for opioids and opiate raw materials used for medical and scientific purposes;

5. Reaffirm the Political Declaration adopted by the General Assembly at its twentieth special session, ${ }^{5}$ the Declaration on the Guiding Principles of Drug Demand Reduction, ${ }^{6}$ the Action Plan on International Cooperation on the Eradication of Illicit Drug Crops and on Alternative Development, ${ }^{7}$ the Action Plan for the Implementation of the Declaration on the Guiding Principles of Drug Demand Reduction ${ }^{8}$ and the Joint Ministerial Statement adopted during the ministerial segment of the forty-sixth session of the Commission on Narcotic Drugs; ${ }^{9}$

${ }^{3}$ General Assembly resolution 217 A (III).

${ }^{4}$ The Single Convention on Narcotic Drugs of 1961 as amended by the 1972 Protocol (United Nations, Treaty Series, vol. 976, No. 14152), the Convention on Psychotropic Substances of 1971 (ibid., vol. 1019, No. 14956) and the United Nations Convention against Illicit Traffic in Narcotic Drugs and Psychotropic Substances of 1988 (ibid., vol. 1582, No. 27627).

${ }^{5}$ General Assembly resolution S-20/2, annex.

${ }^{6}$ General Assembly resolution S-20/3, annex.

${ }^{7}$ General Assembly resolution S-20/4 E.

${ }^{8}$ General Assembly resolution 54/132, annex.

${ }^{9} \mathrm{~A} / 58 / 124$, sect. II.A. 
6. Recall also the United Nations Millennium Declaration, ${ }^{10}$ the provisions of the 2005 World Summit Outcome ${ }^{11}$ addressing the world drug problem, the Political Declaration on HIV/AIDS ${ }^{12}$ and other relevant United Nations resolutions, including General Assembly resolution 63/197 of 18 December 2008 and those on regional and international cooperation to prevent the diversion and smuggling of precursors;

7. Note the commemoration, in Shanghai, China, on 26 and 27 February 2009, of the centennial of the convening of the International Opium Commission;

8. Express deep concern at the high price paid by society and by individuals and their families in the fight against the world drug problem, and pay special tribute to the law enforcement and judicial personnel who have sacrificed their lives and to the healthcare and civil society personnel who have dedicated themselves to addressing this scourge;

9. Acknowledge the important contribution made by women in curbing the world drug problem, commit ourselves to ensuring that drug control policies, measures and interventions take into account the specific needs and circumstances that women face with regard to drug problems, and decide to undertake effective measures to ensure that women, as well as men, have access to, and benefit equally and without discrimination from, drug control policies and strategies by involving them actively in all stages of programme and policy development and implementation;

10. Welcome the important role played by civil society, in particular non-governmental organizations, in addressing the world drug problem, and note with appreciation their important contribution to the review process, also noting that representatives of affected populations and civil society entities, where appropriate, should be enabled to play a participatory role in the formulation and implementation of drug demand and supply reduction policy;

11. Welcome also the reports of the Executive Director of the United Nations Office on Drugs and Crime on the world drug problem, the annual World Drug Report and the annual report of the International Narcotics Control Board and, on the basis of those reports, recognize that some progress has been made, through positive achievements, at the local, regional and international levels in implementing the Political Declaration adopted by the General Assembly at its twentieth special session but also recognize that there are still considerable challenges, as well as emerging challenges, to efforts to sustainably reduce, or at least effectively contain, illicit drug production, trafficking and consumption;

\footnotetext{
${ }^{10}$ See General Assembly resolution 55/2.

${ }^{11}$ See General Assembly resolution 60/1.

12 General Assembly resolution 60/262, annex.
} 
12. Acknowledge the continuing efforts made and progress achieved in countering the world drug problem, note with great concern the unprecedented surge in illicit opium production and trafficking, the continuing illicit cocaine manufacture and trafficking, the increasing illicit cannabis production and trafficking and the increasing diversion of precursors, as well as the related distribution and use of illicit drugs, and stress the need to strengthen and intensify joint efforts at the national, regional and international levels to tackle those global challenges in a more comprehensive manner, in accordance with the principle of a common and shared responsibility, including by means of enhanced and better coordinated technical and financial assistance;

13. Agree that amphetamine-type stimulants and psychotropic substances continue to pose a serious and constantly evolving challenge to international drug control efforts, which threatens the security, health and welfare of the population, especially youth, and requires a focused and comprehensive national, regional and global response, based on scientific evidence and experience, in an international and multisectoral setting;

14. Decide to continue to raise public awareness of the risks and the threats posed to all societies by the different aspects of the world drug problem;

15. Take account of the need for indicators and instruments for the collection and analysis of accurate, reliable and comparable data on all relevant aspects of the world drug problem and, where appropriate, the enhancement or development of new indicators and instruments, and recommend that the Commission on Narcotic Drugs take further measures to address that issue;

16. Reaffirm the principal role of the Commission on Narcotic Drugs and its subsidiary bodies, together with the International Narcotics Control Board, as the United Nations organs with prime responsibility for drug control matters, and decide to promote and facilitate the effective implementation of and follow-up to the present Political Declaration and its Plan of Action;

17. Reaffirm also our support and appreciation for the efforts of the United Nations, including those of the United Nations Office on Drugs and Crime as the leading entity in the United Nations system for countering the world drug problem, reiterate our intention to continue to improve the governance and financial situation of the Office, stressing the need for adequate and stable financial resources to enable the Office to fulfil its mandates effectively, and request the Office to continue its efforts to carry out all its mandates under the international drug control conventions, as well as other relevant international instruments, and to continue to cooperate with relevant regional and international institutions and Governments by providing, inter alia, technical assistance to Member States that request it;

18. Reaffirm further the leading role of the International Narcotics Control Board, as an independent treaty-based body, in monitoring the implementation of the international drug control conventions, in accordance with its mandate, including the control of 
substances frequently used in the illicit manufacture of narcotic drugs and psychotropic substances, welcome the annual reports of the Board and support the Board in implementing all its mandates under those conventions;

19. Call for continued cooperation between Member States, the International Narcotics Control Board and the World Health Organization to ensure the adequate availability of narcotic drugs and psychotropic substances under international control, including opiates, for medical and scientific purposes, while concurrently preventing their diversion into illicit channels, pursuant to the international drug control conventions;

20. Note with great concern the adverse consequences of drug abuse for individuals and society as a whole, reaffirm our commitment to tackle those problems in the context of comprehensive, complementary and multisectoral drug demand reduction strategies, in particular such strategies targeting youth, also note with great concern the alarming rise in the incidence of HIV/AIDS and other blood-borne diseases among injecting drug users, reaffirm our commitment to work towards the goal of universal access to comprehensive prevention programmes and treatment, care and related support services, in full compliance with the international drug control conventions and in accordance with national legislation, taking into account all relevant General Assembly resolutions and, when applicable, the WHO, UNODC, UNAIDS Technical Guide, ${ }^{13}$ and request the United Nations Office on Drugs and Crime to carry out its mandate in this area in close cooperation with relevant organizations and programmes in the United Nations system, such as the World Health Organization, the United Nations Development Programme and the Joint United Nations Programme on HIV/AIDS;

21. Reiterate our commitment to promote, develop, review or strengthen effective, comprehensive, integrated drug demand reduction programmes, based on scientific evidence and covering a range of measures, including primary prevention, early intervention, treatment, care, rehabilitation, social reintegration and related support services, aimed at promoting health and social well-being among individuals, families and communities and reducing the adverse consequences of drug abuse for individuals and society as a whole, taking into account the particular challenges posed by high-risk drug users, in full compliance with the three international drug control conventions and in accordance with national legislation, and commit ourselves to investing increased resources in ensuring access to those interventions on a non-discriminatory basis, including in detention facilities, bearing in mind that those interventions should also consider vulnerabilities that undermine human development, such as poverty and social marginalization;

22. Reaffirm, consistent with the objective of promoting a society free of drug abuse, our determination, within the framework of national, regional and international

${ }^{13}$ WHO, UNODC, UNAIDS Technical Guide for Countries to Set Targets for Universal Access to HIV Prevention, Treatment and Care for Injecting Drug Users (World Health Organization, Geneva, 2009). 
strategies, to counter the world drug problem and to take effective measures to emphasize and facilitate healthy, productive and fulfilling alternatives to the illicit consumption of drugs, which must not become accepted as a way of life;

23. Reaffirm also our commitment to invest in and work with youth in a range of settings, including in families, schools, workplaces and communities, by raising public awareness and providing youth with information, skills and opportunities to choose healthy lifestyles, taking into account the World Programme of Action for Youth to the Year 2000 and Beyond, and working in coordination with the United Nations Programme on Youth of the Department of Economic and Social Affairs of the Secretariat;

\section{Recognize that:}

(a) Sustainable crop control strategies targeting the illicit cultivation of crops used for the production of narcotic drugs and psychotropic substances require international cooperation based on the principle of shared responsibility and an integrated and balanced approach, taking into account the rule of law and, where appropriate, security concerns, with full respect for the sovereignty and territorial integrity of States, the principle of non-intervention in the internal affairs of States and all human rights and fundamental freedoms;

(b) Such crop control strategies include, inter alia:

(i) Alternative development and, where appropriate, preventive alternative development programmes;

(ii) Eradication;

(iii) Law enforcement measures;

(c) Such crop control strategies should be in full conformity with article 14 of the United Nations Convention against Illicit Traffic in Narcotic Drugs and Psychotropic Substances of $1988,{ }^{14}$ appropriately coordinated and phased in accordance with national policies in order to achieve the sustainable eradication of illicit crops, noting furthermore the need for Member States to undertake to increase long-term investment in such strategies, coordinated with other development measures, in order to contribute to the sustainability of social and economic development and poverty eradication in affected rural areas, taking due account of the traditional licit uses of crops where there is historical evidence of such use and giving due consideration to the protection of the environment;

25. Reiterate our commitment to promote and implement balanced policies and strategies on precursor control with a view to preventing the diversion of precursors used in

${ }^{14}$ United Nations, Treaty Series, vol. 1582, No. 27627. 
the illicit manufacture of drugs while ensuring that the legitimate trade in and use of those precursors are not adversely affected;

26. Emphasize that continued and persistent national, regional and international efforts based on improved understanding of the problem through the examination of scientific evidence and the sharing of experiences, forensic data and information are essential to preventing the diversion of precursors and other substances under international control that are used in the illicit production and manufacturing of narcotic drugs and psychotropic substances, including amphetamine-type stimulants;

27. Express deep concern at the growing violence resulting from activities of criminal organizations involved in drug trafficking, and call for urgent measures to prevent those organizations from acquiring the means, in particular firearms and ammunition, to pursue their criminal activities;

28. Stress the urgent need to respond to the serious challenges posed by the increasing links between drug trafficking, corruption and other forms of organized crime, including trafficking in humans, trafficking in firearms, cybercrime and, in some cases, terrorism and money-laundering, including money-laundering in connection with the financing of terrorism, and to the significant challenges faced by law enforcement and judicial authorities in responding to the ever-changing means used by transnational criminal organizations to avoid detection and prosecution;

29. Recognize that, despite our past efforts, illicit crop cultivation and illicit drug production, manufacturing, distribution and trafficking have been increasingly consolidated into a criminally organized industry generating enormous amounts of money, laundered through the financial and non-financial sectors and, therefore, commit ourselves to strengthening the effective and comprehensive implementation of regimes for countering money-laundering and to improving international cooperation, including judicial cooperation, in order to prevent, detect and prosecute such crimes, dismantle criminal organizations and confiscate their illicit proceeds, and also recognize the need to train law enforcement and judicial personnel to utilize the tools available in the international framework, as well as the need to encourage the development of such training;

30. Acknowledge the entry into force of the United Nations Convention against Transnational Organized Crime and the Protocols thereto ${ }^{15}$ and the United Nations Convention against Corruption, ${ }^{16}$ recognize that those conventions and other relevant international instruments constitute valuable tools for confronting the world drug problem, and urge Member States that have not yet done so to consider taking measures to ratify or accede to those instruments;

\footnotetext{
${ }^{15}$ United Nations, Treaty Series, vols. 2225, 2237, 2241 and 2326, No. 39574.

${ }^{16}$ Ibid., vol. 2349, No. 42146.
} 
31. Acknowledge also the importance of promoting, in order to enhance the effectiveness of drug control measures, an integrated approach in drug policies, including addressing comprehensively the impact and consequences of such measures and strengthening their coordination and the assessment of their implementation;

32. Recognize that transit States are faced with multifaceted challenges resulting from illicit drugs being trafficked through their territory, and reaffirm our willingness to cooperate with those States and to assist them in progressively enhancing their capacity to counter the world drug problem;

33. Undertake to promote bilateral, regional and international cooperation, including through intelligence-sharing and cross-border cooperation, aimed at countering the world drug problem more effectively, in particular by encouraging and supporting such cooperation by those States most directly affected by illicit crop cultivation and the illicit production, manufacture, transit, trafficking, distribution and abuse of narcotic drugs and psychotropic substances;

34. Call for increased technical and financial assistance to Member States, in particular those most directly affected by the world drug problem, in order to ensure that they have the capacity to prevent and respond to that threat in all its forms and manifestations;

35. Commit ourselves to increasing cooperation at the regional and international levels, taking due account of situations where States are significantly affected by the illicit cultivation of crops used for the production of narcotic drugs and psychotropic substances and illicit trafficking in drugs and precursors, in order to counter the world drug problem and its impact on political stability, democratic institutions, security, the rule of law and sustainable development, including efforts to eradicate poverty;

36. Decide to establish 2019 as a target date for States to eliminate or reduce significantly and measurably:

(a) The illicit cultivation of opium poppy, coca bush and cannabis plant;

(b) The illicit demand for narcotic drugs and psychotropic substances; and drugrelated health and social risks;

(c) The illicit production, manufacture, marketing and distribution of, and trafficking in, psychotropic substances, including synthetic drugs;

(d) The diversion of and illicit trafficking in precursors;

(e) Money-laundering related to illicit drugs; 
37. Recognize the need to increase investment in research and evaluation in order to properly implement and assess, based on evidence, effective policies and programmes for countering the world drug problem;

38. Adopt the Plan of Action, set out below, which constitutes an integral part of the present Political Declaration and complements the Political Declaration adopted by the General Assembly at its twentieth special session, the Action Plan on International Cooperation on the Eradication of Illicit Drug Crops and on Alternative Development and the Action Plan for the Implementation of the Declaration on the Guiding Principles of Drug Demand Reduction;

39. Commit ourselves to implementing effectively the present Political Declaration and its Plan of Action through resolute international cooperation, in collaboration with relevant regional and international organizations, with the full assistance of the international financial institutions and other relevant agencies and in cooperation with civil society, including non-governmental organizations, as well as the private and public sectors, and to reporting biennially to the Commission on Narcotic Drugs on the efforts to fully implement the Political Declaration and the Plan of Action, and also consider it necessary for the Commission to include on its agenda a separate item on follow-up to the Political Declaration and its Plan of Action;

40. Decide that the Commission on Narcotic Drugs at its fifty-seventh session, in 2014, should conduct a high-level review of the implementation by Member States of the present Political Declaration and its Plan of Action, recommend that the Economic and Social Council devote a high-level segment to a theme related to the world drug problem, and also recommend that the General Assembly hold a special session to address the world drug problem. 



\section{Plan of Action}

\section{Part I. Demand reduction and related measures}

\section{A. Reducing drug abuse and dependence through a comprehensive approach}

\section{Enhancing international cooperation}

\section{Problem}

1. The commitments made by Member States in $1998^{17}$ to attain significant and measurable results in the area of drug demand reduction have been attained only to a limited extent, owing largely to the lack of a balanced and comprehensive approach.

Action

2. Member States should:

(a) Pursue a balanced and mutually reinforcing approach to supply and demand reduction, devoting more effort to the realization of demand reduction with a view to achieving proportionality of effort, resources and international cooperation in addressing drug abuse as a health and social issue, while upholding the law and its enforcement;

(b) Scale up international assistance in addressing drug demand reduction in order to achieve a significant impact; to that end, long-term political and financial commitments from Governments and the international community need to be ensured, including the strengthening of the United Nations Office on Drugs and Crime and other relevant international agencies;

(c) Comprehensively support the reinforcement of the work that the United Nations Office on Drugs and Crime undertakes in drug demand reduction, in consultation with each other and with relevant United Nations and other intergovernmental organizations, in accordance with the Declaration on the Guiding Principles of Drug Demand Reduction, ${ }^{18}$ the Action Plan for the implementation of those principles ${ }^{19}$ and

\footnotetext{
${ }^{17}$ See General Assembly resolutions S-20/2 and S-20/3.

${ }^{18}$ General Assembly resolution S-20/3, annex.

${ }^{19}$ General Assembly resolution 54/132, annex.
} 
the strategy of the United Nations Office on Drugs and Crime for the period 2008$2011 ; 20$

(d) Encourage, in cooperation with multilateral agencies and international and regional financial institutions, short-, medium- and long-term planning and continuous financial support for drug demand reduction programmes;

(e) Encourage international and regional agencies working on drug demand reduction, in particular the United Nations Office on Drugs and Crime, the World Health Organization, the United Nations Development Programme, the Joint United Nations Programme on HIV/AIDS and the International Narcotics Control Board, to engage in dialogue in order to strengthen inter-agency cooperation for a more effective response to drug use and dependence, while respecting each organization's role and mandate;

(f) Also encourage dialogue regarding drug demand reduction with the International Narcotics Control Board, and other relevant United Nations bodies including, as appropriate, human rights bodies, in accordance with the three international drug control conventions; ${ }^{21}$

(g) Develop and implement, in cooperation with international and regional agencies, a sound and long-term advocacy strategy, including harnessing the power of communication media, aimed at reducing discrimination that may be associated with substance abuse, promoting the concept of drug dependence as a multifactorial health and social problem and raising awareness, where appropriate, of interventions based on scientific evidence that are both effective and cost-effective;

(h) Promote the sharing of effective models for demand reduction that address the problem in a comprehensive manner.

\section{Comprehensive approach to drug demand reduction}

\section{Problem}

3. Some countries have implemented effective drug demand reduction policies. However, drug demand reduction measures are often limited in the range of interventions they offer. Measures are frequently planned and carried out in isolation and address only part of the health and socio-economic problems associated with drug use and dependence.

${ }^{20}$ Economic and Social Council resolution 2007/12, annex.

${ }^{21}$ The Single Convention on Narcotic Drugs of 1961 as amended by the 1972 Protocol (United Nations, Treaty Series, vol. 976, No. 14152), the Convention on Psychotropic Substances of 1971 (ibid., vol. 1019, No. 14956) and the United Nations Convention against Illicit Traffic in Narcotic Drugs and Psychotropic Substances of 1988 (ibid., vol. 1582, No. 27627). 
4. Member States should:

(a) Develop, review and strengthen, as appropriate, comprehensive and integrated drug demand reduction policies and programmes, providing a continuum of prevention and care in the health-care and social services, from primary prevention to early intervention to treatment and to rehabilitation and social reintegration, and in related support services, aimed at promoting health and social well-being among individuals, families and communities and reducing the adverse consequences of drug abuse for individuals and society as a whole, taking into account the particular challenges posed by high-risk drug users, in full compliance with the three international drug control conventions and in accordance with national legislation;

(b) Deliver comprehensive policies and programmes using a multi-agency approach, including health-care, social-care, criminal justice, employment and education agencies, non-governmental organizations and civil society, which should take full advantage of the activities of non-governmental and civil society organizations;

(c) Develop, implement and disseminate demand reduction strategies as part of their respective comprehensive and balanced national drug control strategies, clearly describing objectives, interventions and funding, as well as defining roles, responsibilities and mechanisms for different partners in all relevant sectors;

(d) Undertake drug demand reduction efforts to address all forms of drug use, including misuse and dependence related to the consumption of two or more substances at the same time;

(e) Ensure that drug demand reduction efforts address the vulnerabilities, such as poverty and marginalization, that undermine sustainable human development;

(f) Deliver prevention programmes based on scientific evidence, both universal and targeted, in a range of settings (such as schools, families, the media, workplaces, communities, health and social services and prisons);

(g) Consider integrating scientifically established mechanisms for the voluntary and early identification, diagnosis and intervention of drug disorders as part of routine health-care services;

(h) Consider developing a comprehensive treatment system offering a wide range of integrated pharmacological (such as detoxification and opioid agonist and antagonist maintenance) and psychosocial (such as counselling, cognitive behavioural therapy and social support) interventions based on scientific evidence and focused on the process of rehabilitation, recovery and social reintegration; 
(i) Strengthen their efforts aimed at reducing the adverse consequences of drug abuse for individuals and society as a whole, taking into consideration not only the prevention of related infectious diseases, such as HIV, hepatitis B and C and tuberculosis, but also all other health consequences, such as overdose, workplace and traffic accidents and somatic and psychiatric disorders, and social consequences, such as family problems, the effects of drug markets in communities and crime.

\section{Human rights, dignity and fundamental freedoms in the context of drug demand reduction}

\section{Problem}

5. There is an insufficient emphasis on human rights and dignity in the context of drug demand reduction efforts, in particular regarding access to the highest attainable standard of health services. There is also a need for an improved understanding of addiction and the growing recognition of it as a chronic but treatable multifactorial health disorder.

\section{Action}

6. Member States should:

(a) Ensure that drug demand reduction measures respect human rights and the inherent dignity of all individuals and facilitate access for all drug users to prevention services and health-care and social services, with a view to social reintegration;

(b) Promote meaningful livelihood activities and employment to instil a sense of purpose and self-esteem in individuals to steer them away from drugs;

(c) Develop demand reduction programmes that focus on primary prevention, early intervention, treatment, care, rehabilitation and related support services, aimed at promoting health and social well-being among individuals, families and communities and reducing the adverse consequences of drug abuse for individuals and society as a whole, taking into account the particular challenges posed by high-risk drug users, in full compliance with the three international drug control conventions and in accordance with national legislation; and work within existing legal systems to develop mechanisms that link law enforcement processes to health-care systems, including, in the area of drug-related treatment, in accordance with national legislation.

\section{Measures based on scientific evidence}

\section{Problem}

7. In many cases, drug use and dependence interventions aimed at prevention and care have been developed spontaneously by well-intentioned institutions responding to the urgency of a rapidly developing drug problem. Too often, however, those interventions were not based entirely on scientific evidence and a multidisciplinary approach. 


\section{Action}

8. Member States should:

(a) Invest adequate resources in measures based on scientific evidence, building on the significant scientific progress achieved in that area;

(b) Support and widely disseminate, in collaboration with the international community, further research to develop measures based on scientific evidence that are relevant to different socio-cultural environments and social groups;

(c) Encourage innovative measures and incorporate evaluation in order to respond to present and future challenges; and take into account the possibilities given by new media and technologies, including the Internet, with a view to developing the scientific evidence base.

\section{Availability of and accessibility to drug demand reduction services}

\section{Problem}

9. A range of barriers to specific drug demand reduction services makes it difficult for those in need to access those services.

\section{Action}

10. Member States should:

(a) Ensure that access to drug treatment that is affordable, culturally appropriate and based on scientific evidence is available and that drug dependence care services are included in health-care systems, whether public or private, with the involvement of primary and, where appropriate, specialized health-care services, in accordance with national legislation;

(b) Ensure, where appropriate, the sufficient availability of substances for medication-assisted therapy, including those within the scope of control under the international drug control conventions, as part of a comprehensive package of services for the treatment of drug dependence;

(c) Continue to comply with the procedures established under the international drug control conventions and relevant resolutions of the Economic and Social Council relating to the submission to the International Narcotics Control Board of estimates of their requirements for narcotic drugs and assessments of requirements for psychotropic substances so as to facilitate the import of the required narcotic drugs and psychotropic substances and to enable the Board, in cooperation with Governments, to maintain a 
balance between the demand for and the supply of those drugs and substances in order to ensure the relief of pain and suffering and the availability of medication-assisted therapy as part of a comprehensive package of services for the treatment of drug dependence, while bearing in mind, in accordance with national legislation, the World Health Organization Model List of Essential Medicines.

\section{Mainstreaming community involvement and participation}

\section{Problem}

11. In many cases, interventions tend to be supported through isolated and short term initiatives and are not mainstreamed in the regular provision by Governments of public health, education and social services. Moreover, they do not involve all stakeholders at the community level in the planning, delivery, monitoring and evaluation of drug demand reduction measures, and they do not take full advantage of the activities of non-governmental organizations and civil society.

\section{Action}

12. Member States should:

(a) Ensure, to the extent possible, that measures are mainstreamed in the provision of public and private health, education and social services (such as family, housing and employment services);

(b) Involve all stakeholders at the community level (including the target populations, their families, community members, employers and local organizations) in the planning, delivery, monitoring and evaluation of drug demand reduction measures;

(c) Involve communication media in supporting ongoing drug prevention programmes through well-targeted campaigns;

(d) Promote collaboration between governmental and non-governmental organizations and other members of civil society in the establishment of drug demand reduction measures at the local level.

\section{Targeting vulnerable groups and conditions}

\section{Problem}

13. Drug demand reduction interventions too often target the general population at large with a single standard approach and do not provide specialized programmes tailored to vulnerable groups with specific needs. Those groups include, among others, 
children, adolescents, vulnerable youth, women, including pregnant women, people with medical and psychiatric co-morbidities, ethnic minorities and socially marginalized individuals. A person may belong to more than one of these groups and thus have multiple needs.

\section{Action}

\section{Member States should:}

(a) Ensure that a broad range of drug demand reduction services, including those in the areas of prevention, treatment, rehabilitation and related support services, provide approaches that serve the needs of vulnerable groups and are differentiated on the basis of scientific evidence so that they respond best to the needs of those groups, taking into account gender considerations and cultural background;

(b) Ensure that prevention programmes target and involve youth and children with a view to increasing their reach and effectiveness;

(c) Provide specialized training for those who work with vulnerable groups, such as patients with psychiatric co-morbidities, minors and women, including pregnant women.

\section{Drug use and dependence care in the criminal justice system}

\section{Problem}

15. There are limited alternatives to prosecution and imprisonment for drug-using offenders, and treatment services within the criminal justice system are frequently inadequate. Moreover, issues such as corruption, overcrowding and access to drugs and their adverse effects, including the frequency of transmission of infectious diseases within prisons, need to be addressed. Finally, increased emphasis should be placed on the transition between incarceration and release, re-entry and social reintegration.

\section{Action}

\section{Member States should:}

(a) Working within their legal frameworks and in compliance with applicable international law, consider allowing the full implementation of drug dependence treatment and care options for offenders, in particular, when appropriate, providing treatment as an alternative to incarceration;

(b) Take measures to address corruption, reduce overcrowding and prevent access to and use of illicit drugs within detention facilities; 
(c) Implement comprehensive treatment programmes in detention facilities; commit themselves to offering a range of treatment, care and related support services to drug-dependent inmates, including those aimed at prevention of the transmission of related infectious diseases, pharmacological and psychosocial treatment and rehabilitation; and further commit themselves to providing programmes aimed at preparation for release and prisoner support programmes for the transition between incarceration and release, re-entry and social reintegration;

(d) Provide appropriate training so that criminal justice and/or prison staff carry out drug demand reduction measures that are based on scientific evidence and are ethical and so that their attitudes are respectful, non-judgemental and non-stigmatizing.

\section{Quality standards and training of staff}

\section{Problem}

17. Inadequately trained personnel and a lack of certification and quality standards hinder the effective implementation of demand reduction measures based on scientific evidence.

\section{Action}

\section{Member States should:}

(a) Support the development and adoption of appropriate health-care standards, as well as ongoing training on drug demand reduction measures;

(b) Ensure that services are staffed, to the extent possible and as appropriate, with multidisciplinary teams, including physicians/psychiatrists, nurses, psychologists, social workers, educators and other professionals;

(c) Ensure, where appropriate, that the educational curricula for relevant service providers, including the curricula of universities, medical schools and other relevant professions, include training on the prevention of drug use and dependence and related care;

(d) Provide training to planners and practitioners of governmental agencies, non-governmental organizations, the private sector and others in the community, on a permanent basis, on all aspects of demand reduction activities and strategic programming by identifying local, national, subregional and regional human resources and using their experience in the design of programmes to guarantee their continuity and to create and strengthen local, regional, subregional and national training and technical resource networks and, with the possible assistance of regional and international organizations, 
to facilitate the exchange of experiences and expertise by encouraging States to include demand reduction personnel from other States in training programmes that they have developed;

(e) Support national, regional and international networks to provide training and develop and disseminate successful practices.

\section{Data collection, monitoring and evaluation}

\section{Problem}

19. The lack of data, particularly on the rapidly changing nature and the extent of drug use, and the lack of systematic monitoring and evaluation by Governments of the coverage and quality of drug demand reduction measures are matters of great concern. Intensified international cooperation and support is necessary, including for improved and coordinated data collection, monitoring and evaluation of demand reduction programmes to inform demand reduction services and policy.

\section{Action}

20. Member States should:

(a) Increase their efforts in collecting data on the nature and extent of drug use and dependence, including the characteristics of the population in need, strengthening information and monitoring systems and employing methodologies and instruments based on scientific evidence;

(b) Develop and improve methods of objective national assessment by Governments to understand in a systematic and holistic manner the negative impact of drug abuse on society, health and economies;

(c) Ensure that drug demand reduction measures are based on scientifically sound assessments of the nature and extent of the drug problem, as well as the social and cultural characteristics of the population in need;

(d) Ensure that drug demand reduction measures are based on drug use trends in the community and are revised periodically on the basis of new trends, feedback and monitoring and evaluation processes;

(e) Ensure that drug use and dependence prevention and care interventions, as well as other demand reduction measures, include adequate record-keeping systems, while maintaining confidentiality, and that drug dependence care record-keeping systems are part of an active system for monitoring the nature and extent of the drug problem; 
(f) Take an integrated and comprehensive approach to data collection and analysis to ensure that the information available in international, regional and national bodies is fully and legally utilized; and provide technical assistance to those countries where capacity is less developed;

(g) Seek agreement on a set of relevant indicators covering key issues to allow for the comparable assessment of the effectiveness of demand reduction measures with a view to developing, adapting and validating simple, standardized United Nations data-collection and evaluation methods, concepts and tools;

(h) Develop, in cooperation with the international community and in the light of lessons learned in the analysis of replies to the annual reports questionnaire and the biennial reports questionnaire, enhanced data-collection instruments to be considered and adopted by the Commission on Narcotic Drugs, allowing streamlined measurement of the quality, extent and coverage of drug demand reduction measures, ensuring that the tools used are appropriate for the different needs and reporting capacities of countries and are scientifically sound, making full use of existing information resources and, benefiting from, if appropriate, the experience of the existing regional monitoring systems, while minimizing the reporting burden. 


\section{Part II. Supply reduction and related measures}

\section{B. Reducing the illicit supply of drugs}

1. Enhancing cooperation, coordination and law enforcement operations to reduce supply

Problem

21. While the majority of States have adopted and implemented supply reduction policies and made supply reduction an important priority, the commitment made by Member States in 1998 to attain significant and measurable results in the area of supply reduction has been attained only to a limited extent, owing, inter alia, to the lack of effective implementation of drug supply policies, the lack of appropriate national legislative frameworks for international cooperation, inadequate information-sharing and monitoring and control mechanisms and the lack of coordinated law enforcement operations, as well as the insufficient and unstable allocation of resources.

\section{Action}

\section{Member States should:}

(a) In order to reinforce the fight against narcotic drugs and psychotropic substances, ensure, in cooperation with multilateral agencies and international and regional financial institutions, the implementation of short-, medium- and long-term planning so as to ensure a sufficient and stable allocation of resources for drug supply reduction programmes;

(b) Promote the exchange of best practices and successful experiences in the area of drug supply reduction;

(c) Ensure that supply reduction measures are carried out in full conformity with the purposes and the principles of the Charter of the United Nations and international law, the three international drug control conventions and, in particular, with full respect for the sovereignty and territorial integrity of States, the principle of nonintervention in the internal affairs of States and all human rights and fundamental freedoms; 
(d) Continue to rely on the three international drug control conventions as the primary legal framework for tackling the world drug problem, taking into account the relevance of the United Nations Convention against Transnational Organized Crime and the Protocols thereto ${ }^{22}$ and the United Nations Convention against Corruption, ${ }^{23}$ and supporting the pursuit of broader adherence to and implementation of those instruments;

(e) Promote supply reduction measures that take due account of traditional licit uses, where there is historical evidence of such use, as well as environmental protection, in conformity with the United Nations Convention against Illicit Traffic in Narcotic Drugs and Psychotropic Substances of $1988 ;^{24}$

(f) Promote and implement multilateral, regional, subregional and bilateral cooperation among judicial and law enforcement authorities to combat the involvement of criminal organizations in drug production and trafficking and related criminal activities;

(g) Ensure that the international response to the drug problem beyond 2009 continues to be pursued as a common and shared responsibility, requiring a balanced approach for purposes of international cooperation and the provision of technical assistance;

(h) Ensure that international and regional agencies working on drug supply reduction engage in dialogue to strengthen inter-agency cooperation for a more effective response, while respecting each organization's role and mandate;

(i) Further develop and implement effective legislation and legislative frameworks for multilateral, regional, subregional and bilateral cooperation, including agreements on mutual legal assistance and extradition, and address appropriately issues regarding jurisdiction, expedite the processing of mutual legal assistance and extradition requests and, where possible, carry out joint investigations;

(j) Maintain and expand, in collaboration with the international community, projects and programmes to foster bilateral and regional cooperation on specific supply reduction issues;

(k) Consider reassessing the current data-collection strategies and instruments so as to facilitate the compilation of reliable, relevant, comparable and usable data on drug supply in order to ensure a strong and common understanding of the issue, and, in that regard, consider adjusting and standardizing international data collection efforts;

\footnotetext{
${ }^{22}$ United Nations, Treaty Series, vols. 2225, 2237, 2241 and 2326, No. 39574.

${ }^{23}$ Ibid., vol. 2349, No. 42146.

${ }^{24}$ Ibid., vol. 1582, No. 27627.
} 
(l) Remain up to date on scientific studies, data and research on the medicinal and other legitimate uses of plants containing narcotic and psychotropic substances, taking into account the provisions of the three international drug control conventions;

(m) Establish, through the Commission on Narcotic Drugs and in coordination with the Statistical Commission of the Economic and Social Council, clear and measurable indicators in the area of supply reduction in order to accurately assess the achievement of any goals and targets that might be set by the international community beyond 2009;

(n) Provide the United Nations entities having pertinent expertise with resources for the collection of data and the provision of technical and financial assistance to States with a view to enhancing their ability to address trafficking in narcotic drugs and psychotropic substances; coordination with and among United Nations entities and various multilateral entities should be strengthened;

(o) Take additional steps to present a coordinated and coherent response to trafficking in narcotic drugs and psychotropic substances by land, air and sea, in partnership with United Nations entities and international partners, so as to close jurisdictional gaps in the investigation, interdiction and prosecution of traffickers;

(p) Ensure that further encouragement and assistance are provided for the sharing of information through official channels in a timely manner, the implementation of border control measures, the provision of equipment, the exchange of law enforcement officers, collaboration between the private and public sectors and the development of practical new methods for effectively monitoring drug trafficking activities;

(q) Establish, when appropriate, multi-agency bodies to ensure that a comprehensive approach is being taken in tackling drug trafficking networks, while remaining aware that organized criminal groups engaged in drug trafficking are likely to be engaged in other forms of trafficking; the multi-agency bodies will help to ensure that agencies fighting other forms of organized crime share relevant information, intelligence, practices and resources with drug law enforcement agencies.

\section{Addressing new trafficking trends}

\section{Problem}

23. As new trends in drug trafficking emerge, they may pose significant challenges to the ability of States to provide a vigorous and effective response.

Action

24. Member States should: 
(a) Ensure that law enforcement agencies are able to adapt in order to adequately address the changing nature of the drug trafficking problem, particularly with regard to new technologies, routes and methods used by traffickers, thereby reducing the illicit supply of drugs;

(b) Take into account possible linkages between trafficking in narcotic drugs and trafficking in psychotropic substances, the involvement of terrorist groups in some parts of the world, corruption and transnational organized crime, including trafficking in firearms and money-laundering, when developing and implementing supply reduction strategies;

(c) Continue to give attention to the development of methods for gathering and using hard-to-reach intelligence ${ }^{25}$ and evidence, including judicially sanctioned evidence-gathering techniques such as electronic surveillance, structured informant programmes and controlled delivery;

(d) Promote the exchange of intelligence among countries of origin, transit and destination to combat drug trafficking, while safeguarding the sources and the integrity of information;

(e) Monitor, in collaboration with the international community, the nature, use, extent and impact of cybertechnology on trafficking in narcotic drugs and psychotropic substances and give consideration to the development and implementation of legislation and training opportunities in order to respond effectively to the emerging problem;

(f) Make efforts to ensure that appropriate procedural and substantive legislation is developed at the national level to deal with drug trafficking carried out in an electronic environment, including a framework for the effective regulation and oversight of online pharmacies operating or delivering pharmaceutical preparations containing internationally controlled narcotic drugs and/or psychotropic substances within their respective jurisdictions;

(g) Implement strategies to disrupt and dismantle major organizations involved in trafficking in narcotic drugs and psychotropic substances and to address emerging trends;

(h) Provide assistance to transit States to combat trafficking in narcotic drugs and psychotropic substances more efficiently.

\footnotetext{
${ }^{25}$ Lawfully gathered information obtained through the use of structured programmes, such as registered informants, undercover officers, electronic surveillance for intercepting audio and/or video, controlled delivery and other techniques acceptable to the judicial process.
} 


\section{Reducing violence related to drug trafficking}

\section{Problem}

25. In some cases, criminal organizations involved in drug trafficking are exposing civil society and law enforcement authorities to increasing levels of harm and violence, in particular because of their propensity to be heavily armed with illicitly manufactured and trafficked firearms and to engage in violence to protect themselves and their illicitly trafficked drugs. The international community must take steps to not only reduce the illicit supply of drugs but also reduce the violence that accompanies drug trafficking.

Action

26. Member States should:

(a) Consider ratifying or acceding to and, where possible and appropriate, strengthening the implementation of, the Protocol against the Illicit Manufacturing of and Trafficking in Firearms, Their Parts and Components and Ammunition, supplementing the United Nations Convention against Transnational Organized Crime ${ }^{26}$ in order to reduce the illicit manufacturing of and trafficking in firearms as a means of reducing the violence associated with drug trafficking;

(b) Implement preventive and enforcement measures to combat all forms of criminal activity that may be linked to trafficking in narcotic drugs and psychotropic substances, such as money-laundering, trafficking in persons, the smuggling of migrants and, where appropriate, the financing of terrorism, including the detection of cash and other negotiable items that cross international borders;

(c) Provide adequate and targeted training to law enforcement, customs and border control authorities in combating trafficking in narcotic drugs and psychotropic substances and, where appropriate, illicit trafficking in firearms, increase, in the case of States with relevant experience, bilateral and multilateral cooperation, including through programmes administered by the United Nations Office on Drugs and Crime and other international partners, United Nations agencies or regional mechanisms, focused on capacity-building and training, and exchange experiences and best practices so as to increase the ability of all States to more effectively fight trafficking in narcotic drugs and psychotropic substances and, where appropriate, illicit trafficking in firearms;

(d) Increase information-sharing among law enforcement authorities and judicial cooperation in order to identify and investigate possible links between the criminal organizations involved in trafficking in narcotic drugs and psychotropic substances and

${ }^{26}$ United Nations, Treaty Series, vol. 2326, No. 39574. 
other criminal activities, including, in particular, the illicit manufacturing of and trafficking in firearms.

\section{Addressing supply and demand reduction together}

\section{Problem}

27. While drug trafficking is a multifaceted issue that can be effectively tackled only by reducing both supply and demand, this interlinkage is often not taken into account. Supply reduction must involve the application of a balanced approach to reduce demand under the principle of shared responsibility, just as demand reduction must involve the application of a balanced approach to reduce supply under the principle of shared responsibility.

\section{Action}

28. Member States should:

(a) Employ in their national drug control strategies a multidisciplinary approach and include different Government agencies having an interest in combating drug trafficking, including in the areas of health, law enforcement and education, to ensure that all of the factors relevant to reducing supply are taken into account when developing and implementing supply reduction strategies;

(b) Address the need for a comprehensive, multisectoral and balanced approach involving demand reduction and supply reduction, each reinforcing the other, together with the appropriate application of the principle of shared responsibility, while stressing the need for services responsible for prevention, including law enforcement agencies, and ensuring that those measures are mainstreamed in publicly and privately provided health, education, rural development, agriculture and social services.

\section{Strengthening of anti-corruption measures and provision of technical assistance and capacity-building}

\section{Problem}

29. Organized criminal groups, in order to facilitate and protect their illicit trade in drugs, often attempt to influence public officials, including law enforcement authorities. Efforts to reduce supply must be complemented by anti-corruption measures and must employ a comprehensive approach that involves the cooperation of both government and civil society. In this context, several developing countries, especially those on major drug trafficking routes, require technical assistance to further strengthen their law enforcement agencies. 


\section{Action}

30. Member States should:

(a) Consider ratifying or acceding to and strengthening their implementation of the Convention against Corruption, the 1988 Convention and the United Nations Convention against Transnational Organized Crime; ${ }^{27}$

(b) Ensure that proactive strategies are pursued by law enforcement agencies to prevent corruption, such as participating in multilateral and bilateral anti corruption technical assistance programmes, preparing anti-corruption action plans and instituting integrity programmes for law enforcement officials;

(c) Further develop and improve domestic and international training and awareness-raising efforts for law enforcement and judicial capacity-building, while ensuring the coordination of international training and awareness-raising efforts in order to avoid duplication;

(d) Further develop and support the use of controlled delivery, consistent with the 1988 Convention, and other special investigative techniques, both nationally and internationally, consistent with their national legislation;

(e) Enhance efforts to acquire knowledge of the modus operandi of drug traffickers, including through regional and international mapping exercises;

(f) Harness the resources of existing international police structures and institutions to address the issue of trafficking in narcotic drugs and psychotropic substances in a coordinated manner and to ensure a greater degree of efficiency and efficacy;

(g) Provide adequate resources and equipment to border management agencies and provide technical assistance to requesting States in this regard;

(h) Strengthen and integrate law enforcement capabilities to enable them to better investigate organized criminal groups engaged in trafficking in narcotic drugs and psychotropic substances;

(i) Encourage the development and introduction of sustainable and comprehensive programmes in judicial and law enforcement institutions, which should address conditions of service, remuneration, training and awareness-raising so as to attract and retain the best personnel;

${ }^{27}$ Ibid., vol. 2225, No. 39574. 
(j) Ensure that commercial port operations are supported by drug law enforcement authorities with adequate resources, equipment, training and legal powers to effectively screen, evaluate and examine commercial freight and sea bound containers and also ensure that relevant international agencies provide technical assistance to requesting States in this regard.

\section{Control of precursors and of amphetamine-type stimulants}

\section{Improving understanding of the phenomenon of amphetamine-type stimulants}

\section{Problem}

31. Because of the absence of a systematic global mechanism for monitoring the illicit manufacture, prevalence patterns and abuse of and trafficking in amphetamine-type stimulant ${ }^{28}$ and of a global approach to controlling illicit synthetic drugs and the manufacturing and diversion of and trafficking in precursor chemicals, it is still not possible to fully understand the illicit market for synthetic drugs and its characteristics. Many Member States have not yet implemented measures to detect and monitor this part of the illicit drug market and evaluate the responses to it, have limited data on which to base the planning and programming of actions and consequently have limitations with respect to scientific evidence in formulating programmes to tackle it more effectively. In addition, some countries lack the financial and human resources and the know-how to tackle this problem.

\section{Action}

\section{Member States should:}

(a) Take measures to advance the monitoring of illicit synthetic drugs, where it does not already exist, linking existing activities related to amphetamine-type stimulants around the world, and take measures to further the development of monitoring capacity, including for the early identification of emerging trends and to generate prevalence data on amphetamine-type stimulants;

(b) Emphasize the critical importance of forensic and scientific laboratory and treatment centre data and qualitative information in understanding the problem of illicit synthetic drugs and the range of products available on the illicit market and systematically integrate such data and information into their monitoring and investigation activities;

${ }_{28}$ The Synthetics Monitoring: Analysis, Report and Trends (SMART) programme, set up in September 2008, is already in the early stage of development in some regions. 
(c) Promote consultative mechanisms between the International Narcotics Control Board, the United Nations Office on Drugs and Crime and other relevant international and regional bodies in order to enhance the quality and consistency of reported data on amphetamine-type stimulants and other synthetic drugs and their precursors;

(d) Take further measures to advance international information-sharing (i.e. the electronic linking, through the Internet, of national, regional and international documentation centres) to ensure the global dissemination of accurate and timely information, in a standardized manner, on various aspects of the problem of amphetamine-type stimulants (including interdictions, prevalence rates and analysis of policies, legislation and operational responses to inform best practices);

(e) Continue to complement monitoring activities by conducting more systematic research into the problem of amphetamine-type stimulants, including more detailed examinations of the complex interplay between the demand for and the supply of amphetamine-type stimulants in different contexts, and by conducting and making available the results of studies to establish the prevalence and identify the risks of the use of amphetamine-type stimulants.

\section{Targeting the clandestine manufacture of amphetamine-type stimulants}

\section{Problem}

33. Synthetic drugs pose a special problem, as they can be illicitly manufactured in a variety of forms using precursor chemicals, many of which can be easily substituted. In addition, the clandestine and potentially mobile nature of their manufacture requires a global approach in order to understand and prevent the diversion of synthetic drugs and their precursors into illicit channels in all manufacturing, transit and consumer countries.

\section{Action}

34. Member States should:

(a) Develop or strengthen their national capacity for the safe investigation and handling of seized clandestine laboratories for amphetamine-type stimulants, chemical warehouses and precursor chemicals, while building on existing forensic laboratory resources;

(b) Identify best practices for systematically conducting inventories of clandestine laboratory sites, including the laboratory equipment, clandestine manufacturing methods, starting materials, chemicals and reagents used, and improve the exchange of such information in a timely and standardized way; 
(c) Monitor on a voluntary basis, to the extent possible, the sale of laboratory and other equipment, such as tablet presses, in compliance with article 13 of the 1988 Convention.

\section{Preventing illegal sale and diversion}

\section{Problem}

35. The diversion of pharmaceutical preparations, the manufacture and marketing of mixtures of amphetamine-type stimulants and other synthetic drugs, the use of noncontrolled chemicals and/or substitute chemicals as new precursors for the illicit synthesis of drugs and the use and distribution of pharmaceutical products with a view to circumventing appropriate controls on manufacture are crucial challenges for Member States in tackling the problem of amphetamine-type stimulants.

\section{Action}

36. Member States should:

(a) Address through concerted action the illegal sale of preparations containing amphetamine-type stimulants via the Internet and the misuse of postal and courier services for smuggling such preparations;

(b) Take measures to advance cooperation in the detection and investigation of diversion cases and for the sharing of experiences and information among competent national bodies on specific types of diversion;

(c) Strengthen controls, including through the Pre-Export Notification Online system, where required, for the import and export of preparations containing precursor chemicals, such as ephedrine and pseudoephedrine, which could be used in the manufacture of amphetamine-type stimulants;

(d) Advance the systematic collection of data on the abuse of amphetamine-type stimulants and the diversion of precursors and preparations containing amphetaminetype stimulants and use the data to take appropriate countermeasures;

(e) Provide technical assistance, as appropriate, for the development and implementation of adequate controls over the manufacture, sale, diversion and abuse of amphetamine-type stimulants, including legislative, administrative and operational responses, particularly in regions where there is an absence of such controls. 


\section{Raising awareness and reducing demand}

\section{Problem}

37. Despite the potentially serious risks associated with the use of amphetamine-type stimulants and other synthetic drugs, they are nevertheless incorrectly believed to be compatible with healthy lifestyles. It is therefore important to raise greater awareness about the potential risks associated with the use of these substances.

Action

38. Member States should:

(a) Raise awareness of amphetamine-type stimulants and their precursors with law enforcement, health and regulatory authorities and educate vulnerable population groups as to the dangers associated with the use of amphetamine-type stimulants;

(b) Encourage access to comprehensive services, such as treatment, rehabilitation and social reintegration, to address substance abuse, including the abuse of amphetamine-type stimulants, under the supervision of health-care and other appropriate providers, for individuals with problems related to amphetamine-type stimulants, in view of the widespread availability and illicit use of amphetamine-type stimulants by a wide range of population groups;

(c) Develop prevention and treatment programmes tailored to the specific characteristics of the phenomenon of amphetamine-type stimulants as key elements in any relevant strategy to reduce demand and minimize health risks.

\section{Emerging issues in precursor control}

\section{Problem}

39. While legislative and regulatory controls have prevented the diversion of precursor ${ }^{29}$ chemicals into illicit channels, such chemicals still reach clandestine drug laboratories. Precursor chemicals are often diverted from domestic distribution channels in the countries that manufactured or imported them and are smuggled across borders.

${ }^{29}$ The term "precursor" is used to indicate any of the substances listed in Table I or Table II of the United Nations Convention against Illicit Traffic in Narcotic Drugs and Psychotropic Substances of 1988, except where the context requires a different expression. Such substances are often described as precursors or essential chemicals, depending on their principal chemical properties. The plenipotentiary conference that adopted the 1988 Convention did not use any one term to describe such substances. Instead, the expression "substances frequently used in the illicit manufacture of narcotic drugs or psychotropic substances" was introduced in the 1988 Convention. It has become common practice, however, to refer to all such substances simply as "precursors"; although that term is not technically correct, it is used in this text for the sake of brevity. 
Countries not previously targeted by traffickers are now used as areas of diversion. Non-controlled precursor chemicals and/or substitute chemicals, as well as pharmaceutical preparations containing precursors, have been used in the illicit synthesis of drugs. In addition, scientific and forensic support in the identification and safe disposal of precursors is still inadequate in many countries.

40. The absence of a global mechanism for the exchange of laboratory information and law enforcement findings between drug control agencies, customs officials and police remains a global challenge in the control of amphetamine-type stimulants and their precursors.

\section{Action}

\section{Member States should:}

(a) Further strengthen mechanisms, as appropriate, for the timely identification, collection and exchange of information on non-scheduled substances, including derivatives specifically designed to circumvent existing controls, especially by making use of the updated international special surveillance list of non-scheduled substances;

(b) Further strengthen legislation, as appropriate, on the control of precursors and the criminalization of their diversion;

(c) Ensure that measures to control precursors and amphetamine-type stimulants are carried out in full conformity with the purposes and the principles of the Charter of the United Nations and international law, the international drug control conventions and, in particular, with full respect for the sovereignty and territorial integrity of States, the principle of non-intervention in the internal affairs of States and all human rights and fundamental freedoms;

(d) Conduct further research on precursors to understand emerging trends, such as the use of substitute chemicals and the splitting of the production process, including proactive studies on the potential use of such substances, and share the results of such research;

(e) Further advance working relations with the relevant industries to promote the formulation of a universal code of conduct for industry and appropriate national and international legislation on the supply of and trafficking in precursors, including those not yet under international control, and invite the International Narcotics Control Board to provide guidelines on how to establish cooperation between competent national authorities and operators;

(f) Focus greater attention on the use of non-scheduled substances and substitute chemicals for the manufacture of traditional precursors used in the manufacture of heroin and cocaine; 
(g) Cope with the multiple challenges faced by the drug control agencies of developing countries, especially in view of the emergence of new synthetic drugs and amphetamine-type stimulants in those markets, through capacity-building and technical assistance involving, inter alia, the provision of advanced detection equipment, scanners, testing kits, forensic laboratories and training;

(h) Ensure that international and regional agencies working on the control of precursors and amphetamine-type stimulants engage in dialogue to strengthen inter agency cooperation for a more effective response while respecting each agency's role and mandate;

(i) Support efforts by the United Nations Office on Drugs and Crime and the International Narcotics Control Board to assist in the implementation of actions taken within the framework of national and regional cooperation mechanisms;

(j) Support the United Nations Office on Drugs and Crime and the International Narcotics Control Board in conducting, coordinating and disseminating research on precursors in collaboration with the international scientific community to understand emerging trends;

(k) Emphasize the importance of the instruments provided for in article 12 of the 1988 Convention and promote and further enhance their effective implementation, ${ }^{30}$ and also maintain secure means of communication, including secure e-mail addresses;

(l) Endeavour to compile national lists of companies authorized to manufacture, distribute and/or trade in precursors, with a view to enhancing means of verification;

(m) Strengthen national capacity to provide forensic support to law enforcement and the criminal justice authorities in investigating offences involving precursor chemicals, including their trafficking, diversion and use in clandestine laboratories, and assist law enforcement authorities in the detection of precursors on the ground and the early identification of new trends;

(n) Enhance frameworks for the exchange of high-quality and reliable forensic information among drug control agencies, customs authorities and police authorities, including, when appropriate, through the United Nations Office on Drugs and Crime forensic laboratory;

${ }^{30}$ The use of the Pre-Export Notification Online system, including the provision of a timely response, is a key issue in this respect. On a voluntary basis, that system may be used for reporting, to the extent possible and in accordance with national authorities, non-scheduled substances, including pharmaceutical preparations, prior to export, and transit countries should be notified. 
(o) Determine estimates of their legitimate national requirements for ephedrine, pseudoephedrine, 3,4-methylenedioxyphenyl-2-propanone and 1 phenyl-2-propanone, as endorsed by the Commission on Narcotic Drugs in its resolution 49/3, and provide that information to the International Narcotics Control Board, which, in consultation with Member States, should seek to promote standardized methodologies to assist with those estimates to the fullest extent possible;

(p) Strengthen national and regional cooperation among drug control agencies, customs authorities, police authorities, forensic laboratories, relevant industries and operators along the supply chain with a view to preventing the diversion of precursor chemicals;

(q) Make better use of international collaborative and cooperative mechanisms and new and developing technologies to support effective national and international control measures, including the production of strategic data on precursor trends (including information on diversions, as well as on clandestine manufacturing methods and starting materials currently being used in clandestine laboratories);

(r) Develop systems (for example, shared online recording systems) to prevent precursor chemicals from being diverted into illicit channels from community pharmacies;

(s) Increase efforts, beyond international trade controls, to prevent the diversion of precursors, and pharmaceutical preparations containing the precursors ephedrine and pseudoephedrine, from domestic channels to be smuggled across borders, while stressing that the increased involvement of border control authorities in this respect is essential;

(t) Develop practical procedures for the safe handling and disposal of seized precursors in cooperation with competent international and regional bodies and share experiences in that area, as well as training and related activities;

(u) Consider "marking" certain chemical shipments for possible future use if scientific advances ensure the appropriate use of such tools, taking into account the potential burden this would place on authorities and industry;

(v) Continue to support the successes achieved under Project Prism and Project Cohesion, which underline the importance of such activities, including the vital and indispensable role of the International Narcotics Control Board as the global focal point. 


\section{International cooperation on eradicating the illicit cultivation of crops used for the production of narcotic drugs and psychotropic substances and on alternative development ${ }^{31}$}

\section{Strengthening research, data-collection and assessment tools}

\section{Problem}

42. The generation, distribution, sharing and use of credible information on alternative development, including, where appropriate, preventive alternative development, are essential to support the drafting, implementation, monitoring and evaluation of alternative development interventions. However, there continues to be a lack of reliable and up-to-date data on illicit drug crop cultivation, including on, inter alia, the drivers of illicit crop cultivation, no increase in and ineffective utilization of data on human development and socio-economic aspects and insufficient sharing of best practices and lessons learned among the members of the international community engaged in alternative development.

\section{Action}

\section{Member States should:}

(a) Undertake further research, strengthen data collection and guide better alternative development programmes;

(b) Conduct research to assess the factors leading to the illicit cultivation of drug crops used for the production of narcotic drugs and psychotropic substances;

(c) Provide the necessary financial and political support, to the extent possible, to survey, monitor and verify the extent of coca bush, opium poppy and cannabis cultivation, both in indoor and outdoor cultivation sites, consistent with international drug control conventions, and share this information with relevant international agencies and other Governments with a view to increasing cooperation on drug crop eradication and on alternative development, including, where appropriate, on preventive alternative development, in accordance with the specificities of each country or region;

(d) Ensure that States with the necessary expertise, the United Nations Office on Drugs and Crime and other relevant United Nations organizations assist affected States in designing and improving systems to monitor and assess the qualitative and quantitative impact of alternative development and drug crop eradication programmes with respect to the sustainability of illicit crop reduction and socio-

${ }^{31}$ In accordance with Economic and Social Council resolutions 2006/33, 2007/12, annex, and $2008 / 26$, the concept of alternative development includes preventive alternative development. 
economic development; such assessment should include the use of human development indicators that reflect the Millennium Development Goals;

(e) Ensure that affected States, the United Nations Office on Drugs and Crime and other relevant key actors strengthen efforts to share the results of alternative development programmes with the broader development community; in that regard, increased efforts should be made to highlight the work accomplished and the benefits provided to affected communities, and best practices and lessons learned should be identified and shared, failures evaluated and conclusions disseminated to the broader development community.

\section{International cooperation on development-oriented drug control}

\section{Problem}

44. Despite considerable advances over the past 10 years in strengthening international cooperation to address illicit drug crop cultivation through alternative development, the problem of ensuring increased and sustained financial, technical and political assistance by States and the international community continues to hinder the full applicability of alternative development. As such, increased cooperation among States and the international community, under the principle of shared responsibility, a balanced approach and the framework of sustainable development, with a specific focus on preventing, reducing and eliminating the illicit cultivation of crops used for the production of narcotic drugs and psychotropic substances, is necessary to achieve effective and sustainable programmes.

\section{Action}

45. Member States should:

(a) Foster and strengthen international cooperation based on the principle of shared responsibility in sustainable alternative development, including, where appropriate, preventive alternative development; ${ }^{32}$

(b) Reinforce international assistance in addressing the eradication of illicit drug crop cultivation and illicit drug production through integrated and sustainable alternative development; in this connection, long-term political and financial commitments on the part of Governments and the international community should be promoted to the extent possible;

(c) Establish, where possible, sustainable alternative development programmes, in particular in drug-producing regions, including those with high levels of poverty, as

\footnotetext{
${ }^{32}$ Economic and Social Council resolution 2007/12, annex, para. 18 (c).
} 
they are more vulnerable to exploitation by traffickers and more likely to be affected by the illicit cultivation of drug crops and the illicit production of and trafficking in narcotic drugs and psychotropic substances;

(d) Consider, where appropriate, including in their national development strategies, integrated and sustainable alternative development programmes, recognizing that poverty and vulnerability are some of the factors behind illicit drug crop cultivation and that poverty eradication is a principal objective of the Millennium Development Goals; and request development organizations and international financial institutions to ensure that alternative development strategies, including, when appropriate, preventive alternative development programmes, are incorporated into poverty reduction strategy papers and country assistance strategies for States affected by the illicit cultivation of crops used for the production of narcotic drugs and psychotropic substances;

(e) Support the United Nations Office on Drugs and Crime so that it can continue to exercise its catalytic role with a view to mobilizing technical, financial and political support from international financial institutions, non-governmental organizations, relevant United Nations organizations, the private sector and civil society and so that it can also continue its work in supporting States in the design, implementation, monitoring and evaluation of alternative development programmes;

(f) Ensure that the design and implementation of alternative development programmes, including, when appropriate, a preventive approach, involve all stakeholders, take into account the specific characteristics of the target area and incorporate grass-roots communities in project formulation, implementation and monitoring;

(g) Ensure that international and regional agencies working on alternative development engage in dialogue in order to strengthen inter-agency cooperation while respecting each organization's role and mandate;

(h) Promote plans, strategies and guiding principles among members of the development community, in particular international financial institutions, to integrate measures to address the causes of the illicit cultivation of crops used for the production of narcotic drugs and psychotropic substances and to incorporate alternative development strategies into their wider development agendas where such strategies do not already exist;

(i) Ensure, in collaboration with multilateral agencies and international and regional financial institutions, that short-, medium- and long-term planning allows for the continuous financial support of integrated and sustainable alternative development programmes, including preventive alternative development programmes where appropriate, particularly in vulnerable areas;

(j) Take into account, where appropriate, governance and security concerns when implementing alternative development programmes, highlight, where appropriate, 
the status of national drug control strategies and programmes, including the eradication of illicitly cultivated crops used for the production of narcotic drugs and psychotropic substances and ensure that a balanced approach to national drug control and alternative development strategies is adequately applied;

(k) Reach out to States not affected by illicit drug crop cultivation and to the private sector with a view to providing greater access to markets for alternative development products, consistent with national and international obligations and taking into account applicable multilateral trade rules;

(l) Make use of existing cooperation mechanisms and develop regional cooperation mechanisms to exchange experiences in the areas of alternative development and eradication of illicitly cultivated crops used for the production of narcotic drugs and psychotropic substances;

(m) Assist States affected by illicit drug crop cultivation to strengthen cross border, subregional and regional technical assistance and cooperation, including SouthSouth cooperation; and request the United Nations Office on Drugs and Crime, the international development community and other key stakeholders to promote and support relevant cooperation in this regard;

(n) Cooperate with development partners to harmonize, align and manage international development assistance provided to the States affected by illicit drug crop cultivation in accordance with the principles of the 2005 Paris Declaration on Aid Effectiveness: Ownership, Harmonization, Alignment, Results and Mutual Accountability;

(o) Encourage relevant international financial institutions, United Nations organizations, non-governmental organizations and the private sector to increase their rural development support for regions and populations affected by illicit drug crop cultivation through long-term and flexible funding, and, to the extent possible, affected States should make a stronger commitment to financing alternative development programmes.

\section{A balanced, long-term approach to addressing the illicit cultivation of crops used for the production of narcotic drugs and psychotropic substances}

\section{Problem}

46. Despite some significant progress made in certain areas, efforts have not led to a significant overall decrease in the global illicit cultivation of crops used for the production of narcotic drugs and psychotropic substances. The lack of understanding of demand/supply drug market dynamics and the lack of a long-term balanced approach, combined with ill-sequenced policy interventions, corruption and inadequate 
international development assistance to address the causes driving illicit crop cultivation, have impeded the ability of Governments to sustain the gains achieved locally.

\section{Action}

\section{Member States should:}

(a) Tackle alternative development in a larger development context through a holistic and integrated approach, taking into account the Millennium Development Goals, with the priority of eradicating poverty;

(b) Develop alternative development programmes and eradication measures while fully respecting relevant international instruments, including human rights instruments, and, when designing alternative development interventions, taking into consideration the cultural and social traditions of participating communities;

(c) Ensure that development assistance provided to communities in areas affected by illicit cultivation of crops used for the production of narcotic drugs and psychotropic substances takes into account the overall aims of human rights protection and poverty eradication;

(d) Ensure that the implementation of alternative development and preventive alternative development, as appropriate, enhances synergy and trust among the national Government, local administrations and communities in building local ownership;

(e) Integrate communities in marginalized regions into the economic and political mainstream in order to further drug control efforts and security; if appropriate, such integration should include the possibility of supporting access to roads, schools, primary health-care services, electricity and other services and infrastructure;

(f) Ensure the proper and coordinated sequencing of development interventions when designing alternative development programmes; and, in this connection, the issues of the establishment of agreements and viable partnerships with small producers, favourable climatic conditions, strong political support and adequate market access should be taken into account;

(g) Ensure, when considering taking eradication measures, that small-farmer households have adopted viable and sustainable livelihoods so that the measures may be properly sequenced in a sustainable fashion and appropriately coordinated;

(h) Support, in particular in collaboration with development partners, international financial institutions and the United Nations Office on Drugs and Crime, within its mandate, States engaged in alternative development by carrying out preventive alternative development activities, where appropriate, or proactive development 
measures to prevent the expansion of the illicit cultivation of crops used for the production of narcotic drugs and psychotropic substances and the migration of workers to areas affected by illicit drug crop cultivation and illicit drug production zones;

(i) Ensure that development partners, international financial institutions and the United Nations Office on Drugs and Crime support States in addressing the illicit cultivation of coca bush, opium poppy and cannabis through sequenced activities, such as conducting further research to assess the extent of cultivation, identifying the social and economic drivers of cultivation and, ultimately, designing appropriate interventions to tackle the problem;

(j) Address the need to enhance international cooperation and increase comprehensively the effectiveness of strategies aimed at strengthening the capacity of States to counter illicit cultivation of crops used for the production of narcotic drugs and psychotropic substances and at promoting the realization of alternative development programmes;

(k) Develop market infrastructure in support of alternative development programmes, sharing best practices among Governments and regions, as appropriate;

(l) Promote a coordinated response to alternative development and eradication;

(m) Implement, where there is illicit cultivation of crops used for the production of narcotic drugs and psychotropic substances, comprehensive multisectoral interventions that take into account social, cultural, economic, political, educational and environmental aspects while incorporating, where appropriate, demand reduction measures;

(n) Mainstream drug control and alternative development approaches into the broader development agenda, while encouraging the development community, in particular the international financial institutions, to incorporate drug control approaches into their wider development agendas.

\section{Innovative strategies to support alternative development}

\section{Problem}

48. Emerging threats and new challenges competing for global attention have led to a significant reduction in the means available to support the implementation of alternative development programmes, including preventive alternative development programmes, where appropriate. There is an increasing need to identify new and innovative funding mechanisms and to ensure that alternative development programmes are complementary to and incorporated into programmes aimed at addressing environmental 
issues. Likewise, the identification of market-driven products must be undertaken with the private sector, and market access must be assured in order to effectively implement alternative development strategies.

\section{Action}

\section{Member States should:}

(a) Encourage all Member States and multilateral, international and regional financial institutions, in conformity with the principle of shared responsibility, to redouble their efforts to enhance international cooperation, aimed at utilizing the expertise of developing countries and the financial support of developed countries in assisting developing countries, to reduce the illicit cultivation of drug crops through alternative development and preventive alternative development, as appropriate;

(b) Develop strategies consistent with domestic legal frameworks, including the utilization of local expertise, capacity-building and entrepreneurship, to develop products through alternative development programmes identified on the basis of market demand and value-added production chains, as well as secure and stable markets with fair prices for producers, in accordance with international trade rules, including the required infrastructure and a conducive environment, including roads, the establishment of farmer associations and the use of special marketing regimes, for example those based on fair-trade principles and commerce in organic products;

(c) Consider supporting public information campaigns to raise awareness about the concept of shared responsibility and about the added social value of alternative development products;

(d) Assist States affected by the illicit cultivation of crops used for the production of narcotic drugs and psychotropic substances to take advantage of existing mechanisms, such as debt swaps, and existing trade arrangements, and to explore the possibility of increasing national financing for alternative development programmes;

(e) Ensure that development partners, affected States and other relevant key development actors examine innovative ways to promote alternative development programmes, including preventive alternative development programmes, where appropriate, that are environmentally friendly;

(f) Continue to promote gender equality in alternative development interventions, ensuring that equal conditions exist for full participation in the design, implementation and evaluation of alternative development programmes;

(g) Encourage participatory approaches from all stakeholders, including groups at risk of starting to illicitly cultivate crops used for the production of narcotic drugs 
and psychotropic substances, in the identification, preparation, implementation, monitoring and evaluation of alternative development;

(h) Support, together with development partners, affected States and other relevant development agencies, the institutional strengthening of key national line agencies involved in alternative development, particularly national drug control coordinating bodies, recognizing that the sustainability of programmes depends on strengthened national institutions and their ability to bring together Government agencies and to coordinate with the international community;

(i) Examine the possibility of supporting regional mechanisms and promoting bilateral agreements between States in order to address the problem of geographical displacement. 


\section{Part III. Countering money-laundering and promoting judicial cooperation to enhance international cooperation}

\section{E. Countering money-laundering}

\section{Problem}

50. The laundering of money derived from illicit drug trafficking and other serious crimes continues to be a global problem that threatens the security and stability of financial institutions and systems, undermines economic prosperity and weakens governance systems.

\section{Action}

51. Member States should continue to foster international cooperation by implementing the provisions against money-laundering contained in all relevant international and multilateral instruments, such as the 1988 Convention, the Organized Crime Convention and the Convention against Corruption and, in accordance with national legislation, the Financial Action Task Force Recommendations on Money Laundering, and also by:

(a) Establishing new or strengthening existing domestic legislative frameworks to criminalize the laundering of money derived from drug trafficking, precursor diversion and other serious crimes of a transnational nature in order to provide for the prevention, detection, investigation and prosecution of money laundering by, inter alia:

(i) Widening the scope of predicate crimes for money-laundering to include all serious crimes, giving due consideration to crimes related to the misuse of new technologies, cyberspace and electronic money transfer systems and to transnational cash smuggling;

(ii) Adopting or strengthening legal measures providing for the identification, freezing, seizure and confiscation of the proceeds of crime and considering, where compatible with fundamental principle of domestic law, nonconviction-based confiscation;

(iii) Promoting the use of internationally accepted asset-sharing procedures in international confiscation cases, such as the Model Bilateral Agreement on 
the Sharing of Confiscated Proceeds of Crime or Property, adopted by the Economic and Social Council in its resolution 2005/14;

(iv) Ensuring that legal provisions in compliance with due process of law, such as banking secrecy laws, do not unnecessarily impede the effectiveness of their systems for countering money-laundering and do not constitute grounds for the refusal of mutual legal assistance;

(v) Granting the widest range of mutual legal assistance in investigations, prosecutions and other judicial proceedings related to money-laundering and confiscation cases;

(vi) Ensuring that the crime of money-laundering is covered by mutual legal assistance agreements for the purpose of ensuring judicial assistance in investigations, court cases and other judicial proceedings relating to that crime;

(vii) Making money-laundering an extraditable offence, in accordance with national legislation;

(b) Establishing new or strengthening existing financial and regulatory regimes for banks and non-bank financial institutions, including natural and legal persons providing formal or informal financial services, thus preserving the integrity, reliability and stability of financial and trade systems through, inter alia:

(i) Customer identification and verification requirements, namely, application of the "know-your-customer" principle in order to have available for competent authorities the necessary information on the identity of clients and their financial transactions;

(ii) Requirements for the submission of meaningful beneficial ownership information for legal persons;

(iii) Financial record-keeping;

(iv) The mandatory reporting of suspicious transactions;

(v) Mechanisms to detect and monitor the cross-border transport of cash and other negotiable bearer instruments;

(vi) Consideration of establishing partnerships with the private sector, including financial businesses, with a view to ensuring sound and effective duediligence procedures to counter money-laundering;

(vii) The introduction of measures to keep centralized statistical data on legal action taken to counter money-laundering; 
(c) Implementing effective detection, investigation, prosecution and conviction measures, including:

(i) The establishment of dedicated financial intelligence units to serve as national centres for the collection, analysis and dissemination of suspicious transaction reports and the consideration of existing and affordable information technology solutions to assist financial intelligence units in the analysis of suspicious transaction reports;

(ii) The development of specialized law enforcement techniques, consistent with national legislative frameworks, to support efforts to counter money laundering;

(iii) The encouragement of specialized training for law enforcement and judicial personnel in techniques for countering money-laundering;

(iv) The consideration, in conformity with domestic legislation, of utilizing confiscated funds to support law enforcement activities, demand reduction programmes and efforts to counter money-laundering;

(v) The development and use of instruments to detect and counter, in a timely manner, emerging methods and techniques for laundering money, including money derived from drug trafficking, from the diversion of precursors and from the abuse of cyberspace, money transfer systems and payment cards; and the provision of technical assistance for building the capacity of developing countries in this regard, including the development of national detection instruments;

(d) Promoting effective cooperation in strategies for countering moneylaundering and in money-laundering cases by, inter alia:

(i) Strengthening mechanisms for domestic inter-agency coordination and information-sharing;

(ii) Strengthening regional and international networks for the exchange of operational information among competent authorities, in particular financial intelligence units;

(iii) Avoiding, to the extent possible, the duplication of data-collection tools related to Member States' obligations with respect to countering moneylaundering, as set out in relevant United Nations instruments. 


\section{F. Judicial cooperation}

\section{Extradition}

\section{Problem}

52. Legal impediments to extradition and practical difficulties remain, even though most States have laws in place and have entered into bilateral and multilateral treaties on the extradition of drug offenders, and many States have revised their legislation since the twentieth special session of the General Assembly. Concerning the non-extradition of nationals, several States maintain the position that they will not consider extraditing their nationals.

53. Much progress has been achieved through the adoption of relevant bilateral, regional and international agreements, especially at the regional level. While the low number of reported refusals is encouraging, there remain many difficulties with regard to differences between legal systems, delays and procedural and language problems.

\section{Action}

54. Member States should:

(a) Make full use of multilateral treaties, notably, the 1988 Convention, the Organized Crime Convention and the Convention against Corruption, subject to their constitutional and judicial provisions and consistent with relevant international law, as a legal basis for requesting and granting extradition as a supplement to bilateral and regional treaties on judicial cooperation;

(b) Make use of the 1988 Convention, the Organized Crime Convention and the Convention against Corruption, as appropriate, for the purpose of providing a basis for establishing dual criminality required for drug offences, in accordance with their national legislation;

(c) Establish mechanisms to facilitate extradition in line with the international drug control conventions, subject to their national legislation, specifically by considering further simplification of requirements in such areas as dual criminality, the application of political offences, consent surrender and conditional surrender;

(d) Ensure that when, on grounds of nationality, they do not extradite a person, they submit, in conformity with their domestic legislation, as appropriate, the case to their competent national authorities for prosecution; 
(e) Advance cooperation in the areas of extradition, mutual legal assistance and law enforcement, as well as the effective use of tools and programmes to enhance cooperation efforts, consistent with relevant and applicable international human rights obligations and in accordance with their national legislation;

(f) Adopt measures to expedite extradition procedures and simplify evidentiary requirements in conformity with their domestic laws.

\section{Mutual legal assistance}

\section{Problem}

55. While most States have adopted legislation and entered into bilateral and multilateral treaties on mutual legal assistance in drug trafficking cases, and many have revised their procedures since the twentieth special session of the General Assembly, it is difficult to assess the rate of implementation of those provisions. While some progress has been made in this area, problems remain, particularly in relation to differences in procedural requirements, the protection of bank secrecy, the protection of national interests, translation requirements and delays. Statistics on requests for mutual legal assistance are also lacking.

\section{Action}

56. Member States should:

(a) Make full use of multilateral treaties, notably the 1988 Convention, the Organized Crime Convention and the Convention against Corruption, subject to their constitutional provisions, as a legal basis for requesting and granting mutual legal assistance and as a supplement to bilateral and regional treaties on judicial cooperation;

(b) Consider the adoption of a more flexible approach to judicial cooperation in order to facilitate the provision of the widest possible range of mutual legal assistance, in particular in the area of non-coercive measures;

(c) Maintain timely and clear communication among all central authorities, with particular attention to regular consultations with States that have a high volume of requests for assistance, and undertake prior consultations in complex or time-sensitive cases;

(d) Ensure that procedures and practices in relation to mutual legal assistance, extradition and controlled delivery capacity between States take account of different legal systems; and consider, where appropriate, the posting of criminal justice liaison personnel abroad; 
(e) Request the United Nations Office on Drugs and Crime, in cooperation with Member States, to consider the advisability and feasibility of establishing a virtual network of central authorities for mutual legal assistance and competent authorities for extradition requests, pursuant to the 1988 Convention and the Organized Crime Convention, in order to facilitate communication and problem solving among such authorities.

\section{Transfer of proceedings}

\section{Problem}

57. A limited number of States have entered into bilateral and multilateral agreements or revised their legislation to facilitate the transfer of proceedings. The availability of data was lower than in other areas.

\section{Action}

58. Member States should:

(a) Consider adopting legislation or procedures to enable the transfer of proceedings, where appropriate, in particular where extradition is not possible;

(b) Make available information on their experiences in the transfer of proceedings to interested States if they have had such experiences;

(c) Consider entering into agreements with other States to transfer or receive proceedings in criminal matters, particularly with those States which do not extradite their nationals and, in that connection, refer to the Model Treaty on the Transfer of Proceedings in Criminal Matters ${ }^{33}$ as a basis for negotiation.

\section{Controlled delivery}

\section{Problem}

59. Practical difficulties remain in the implementation of controlled delivery. Some of the difficulties relate to differences in legal provisions and authorities responsible for conducting controlled deliveries in different States, as well as to identifying the links between local and international criminal groups.

${ }^{33}$ General Assembly resolution 45/118, annex. 


\section{Action}

60. Member States should:

(a) Ensure, if permitted under the basic principles of their legal systems, that legislation, procedures and practices allow for the use of controlled delivery at the national and international levels and, to that end, enter into necessary agreements, arrangements and understandings;

(b) Enhance cooperation in the areas of controlled delivery requirements, national capacities and sharing of information pertaining to controlled delivery, in conformity with domestic law;

(c) Improve and consider institutionalizing the exchange of information among source, transit and destination countries and among intergovernmental organizations in the area of law enforcement cooperation; States, in particular those situated along major drug trafficking routes, should, in conformity with their national legislation, consider establishing joint investigations and teams of law enforcement officers dealing with drug trafficking and organized crime.

\section{Witness protection}

\section{Problem}

61. Disparities remain among States with respect to legislative provisions, rules, procedures and capacities for the protection of witnesses.

\section{Action}

62. Member States should take appropriate measures, within their means, including adopting, where they have not yet done so, legislation, rules and practical measures that provide for the protection of witnesses before, during and after trial and that allow, where appropriate, the implementation of measures consistent with those set out in the Organized Crime Convention, which should be used to the fullest extent possible, as it includes state-of-the-art measures in this area.

\section{Complementary measures}

\section{Problem}

63. Although legal and procedural frameworks exist in many States, numerous difficulties remain in the implementation of all the measures, in particular the legal, procedural and technical aspects with respect to the execution of requests for judicial cooperation. 


\section{Action}

\section{Member States should:}

(a) Identify areas of synergy between the work of the United Nations Office on Drugs and Crime on judicial cooperation in the area of drug trafficking in the context of the 1988 Convention and the work carried out to implement the Organized Crime Convention and the Convention against Corruption, recognizing that gathering information on the implementation of those instruments must be complementary and mutually supportive;

(b) Assist the United Nations Office on Drugs and Crime in expanding online tools, such as the directory of designated authorities, to enable the sharing of judicial cooperation tools, including model forms, guidelines and manuals for extradition, mutual legal assistance, transfer of proceedings and other types of judicial cooperation or include links to websites containing such information;

(c) Enable the United Nations Office on Drugs and Crime to assist them, upon request, in collecting data for international cooperation and, where appropriate, in establishing databases to maintain such information;

(d) Use, in conformity with national legislation, existing tools and programmes to enhance extradition and mutual legal assistance through information-gathering, judicial assistance resources, including online resources such as directories, model forms, guidelines and manuals;

(e) Promote training and workshops to help acquaint States with different legal systems and strengthen working relationships among counterparts in order to facilitate the execution of requests for assistance and build trust among central authorities;

(f) Strengthen the role of the United Nations Office on Drugs and Crime in providing training and in facilitating problem-solving forums in recognition of the need for States to familiarize themselves with different legal systems and to establish new or strengthen existing working relationships with counterparts;

(g) Review national legislation, as appropriate, to ensure compliance with the legal requirements of the 1988 Convention, as well as to promote the exchange of information among competent authorities regarding drug trafficking by sea, through regional and subregional cooperation;

(h) Define the liability and responsibilities of various shipping structures and strengthen cooperation with professional trade associations, consistent with existing international mechanisms and in accordance with their national legislation. 



Vienna International Centre, PO Box 500, 1400 Vienna, Austria

Tel.: (+43-1) 26060-0, Fax: (+43-1) 26060-5866, www.unodc.org 